\title{
Os primórdios da black music brasileira e da linguagem política do orgulho negro nos anos 1960
}

Bruno Vinícius Leite de Morais ${ }^{1}$

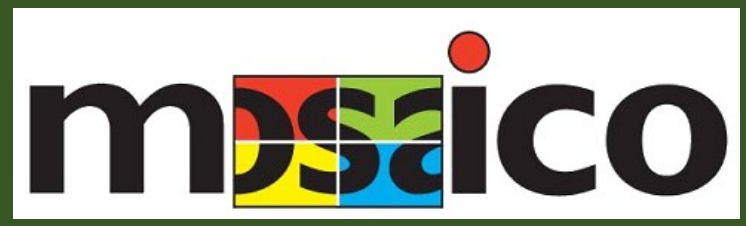

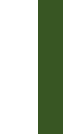


Resumo: Este artigo utiliza a documentação fonográfica para situar o surgimento da Black Music Brasileira nos anos 1960, a partir de hibridações e incorporações de gêneros musicais estadunidenses. Nos primeiros discos lançados por Elza Soares, Jorge Ben, Wilson Simonal e Dom Salvador é identificada a articulação de subgêneros negros do jazz, no que foi chamado de Bossa Negra. Na segunda metade da década ocorre uma incorporação mais explícita do soul e o funk, consolidando a estética Black no Brasil. Nos discos pesquisados também é identificada uma abordagem temática que valoriza a cultura negra e denuncia o preconceito racial. O diálogo com elementos estrangeiros na expressão da realidade racial nas músicas e letras compõe o que está sendo proposto por Linguagem Política do Orgulho Negro.

Palavras-chave: Black Music Brasileira; Orgulho Negro; Questão racial; Brasil anos 1960

Abstract: This article uses phonographic documentation to situate the initial state of Brazilian Black Music in the 1960s, based on hybridizations and incorporations of American musical genres. In the first records released by Elza Soares, Jorge Ben, Wilson Simonal and Dom Salvador, the articulation of black subgenres of jazz is identified, in what was called Bossa Negra. In the second half of the decade there was a more explicit incorporation of soul and funk, consolidating the Black aesthetic in Brazil. The researched discs also identify a thematic approach that values black culture and denounces racial prejudice. The dialogue with foreign elements in the expression of racial reality in music and lyrics composes what is being proposed by Political Language of Black Pride.

Keywords: Brazilian Black Music; Black Pride; Racial issue; 1960s Brazil. 


\section{Introdução}

Um fenômeno de ramificações mercadológicas e políticas tomou a indústria fonográfica brasileira na década de 1970: a Black Music. Criticada por setores nacionalistas como "importação", a Black Music produzida no Brasil e em português geralmente tem sua origem atribuída ao compositor e intérprete Tim Maia, em 1970. Além de um relevante produto no mercado de bens culturais, o gênero apresentou dimensão política ao difundir uma forma de expressão negra alternativa à representação hegemônica no discurso racial brasileiro, permeada pela mestiçagem que alicerça nossa compreensão de "democracia racial".

A relevância mercadológica da Black Music Brasileira, ou Black Soul, como também era chamada nos anos 1970, foi confirmada em 2001, quando a filial brasileira da multinacional Universal relançou em CDs parte de seu antigo catálogo. Uma reportagem da Folha de São Paulo, "Samba \& Soul safras 60 e 70. Série de 12 obras repõe clássicos da música black nacional", publicada no caderno llustrada em 03/08/2001, pontuou a importância cultural da vertente musical:

a seleção, feita pelo titã Charles Gavin, aposta na reputação popular da black dos anos 70 no Brasil, hoje gozando de relativa revalorização. Tudo começa pela raiz do que na década de 70 se tornaria um caldeirão de fusões entre samba, bossa nova, jazz, rhythm'n'blues, soul, funk e, mais adiante, discothèque: os três álbuns iniciais do carioca Jorge Ben (hoje Ben Jor), definidor, com Wilson Simonal, de novos rumos para o samba e para o orgulho negro no Brasil. (...) De Jorge, a coleção viaja à soul music de Cassiano e Hyldon, fundadores do gênero no Brasil com Tim Maia, lá pelo final dos $60 .^{2}$

O trecho de reportagem aborda os temas que configuram o objeto do presente artigo, ao ressaltar uma "raiz" desta música black na década de 1960 com Jorge Ben e Wilson Simonal, ainda que atribua à Tim Maia, Hyldon e Cassiano o papel de "fundadores" da soul music no Brasil. A intenção deste artigo é abordar o desenvolvimento de uma proposta musical brasileira, realizada por artistas negros, que na década de 1960 incorporou e reelaborou a Black Music estadunidense, em um processo de hibridação no qual, conforme propõe o argentino Canclini, não

\footnotetext{
${ }^{2}<$ https://www1.folha.uol.com.br/fsp/ilustrad/fq0308200127.htm> Acesso 30/09/2020
} 
Os primórdios da black music brasileira e da linguagem política do orgulho negro nos anos 1960

ocorre fusões sem contradições, mas "processos socioculturais nos quais estruturas ou práticas discretas, que existiam de forma separada, se combinam para gerar novas estruturas, objetos e práticas" (CANCLINI, 2008, XVIII-XIX).

Os primeiros passos da Black Music Brasileira iniciam na Bossa Negra de Elza Soares, passam pelo Sambajazz de Jorge Ben, Simonal e Salvador Trio, e chegam a uma sonoridade abertamente soul e funk, com Simonal e Dom Salvador. Ao acompanhar o desenvolvimento dessa sonoridade é possível identificar o ambiente que teve continuidade e ápice no Black Soul de Tim Maia, Cassiano, Toni Tornado e outros nos anos 1970. Ouvir o repertório sessentista permite ainda observar uma abordagem temática que valoriza a "cultura negra", expressa elementos religiosos de matriz afro e também do cotidiano das comunidades negras, incluindo referências ao preconceito racial. Os limites deste artigo impedem uma análise verticalizada das canções, porém, permitem assinalar a circulação de elementos estéticos e políticos na música brasileira que compõem o que será proposto por Linguagem Política do Orgulho Negro: uma forma de expressão da questão racial que, a partir do diálogo com experiências da diáspora negra, particularmente a estadunidense, tensiona o discurso hegemônico da "Democracia racial".

\section{A democracia racial como contexto}

A expressão "democracia racial" tornou-se, no decorrer do século $\mathrm{XX}$, um vocábulo condensador de um ideal arraigado que compreende as relações raciais brasileiras como harmônicas. Seja através do discurso que alega ter existido uma instituição escravista "branda" no Brasil ou no que afirma a inexistência de preconceito e discriminação no país, esse ideal de harmonia serviu e ainda serve para mascarar diversas manifestações de violência existentes no passado e no presente do país. Configurando não apenas um discurso oficial, mas uma forma de representação da identidade nacional, o ideal de harmonia espraiou-se na linguagem cotidiana da população, de modo que ao discutir sobre a questão racial no Brasil, comumente a "democracia racial" aparece como o "pano de fundo", o contexto da discussão. 
A compreensão de relações raciais harmônicas no Brasil é tão antiga quanto a existência do país como Estado nacional, configurando uma das mais bem sucedidas construções do ideal conciliador e de aversão a conflitos da população brasileira. No primeiro concurso para a criação de uma narrativa histórica do Brasil, 18 anos após a independência do país, a tese ganhadora, escrita pelo alemão Von Martius, apresentou a nação através da metáfora de um caudaloso rio originado da convergência de três afluentes, um grande e branco (europeu), um mediano e negro (africano) e outro menor indígena (autóctone) (IGLÉSIAS, 2000, p. 65-72). E ainda no século XIX, a retórica da harmonia racial foi mobilizada para reprimir a organização de pessoas negras, conforme o parecer de rejeição do Conselho de Estado do Império ao estatuto da Associação Beneficente Socorro Mútuo dos Homens de Cor no ano de 1875:

Os homens de cor, livres, são no Império cidadãos que não formam classe separada, e quando escravos não têm direito a associar-se. A Sociedade especial é pois dispensável e pode trazer os inconvenientes da criação do antagonismo social e político: dispensável, porque os homens de cor devem ter e de fato têm admissão nas Associações Nacionais, como é seu direito e muito convém à harmonia e boas relações entre os brasileiros. (GOMES, 2005, p. 9).

Contudo, foi no século XX que a representação de harmonia racial consolidou no discurso do Estado brasileiro como uma característica singular da nacionalidade. Um destaque nesse processo foi a adoção oficial da produção intelectual de Gilberto Freyre, que, na década de 1930, interpretou o Brasil como uma "democracia étnica" e "democracia social". Antônio Sergio A. Guimarães, ao analisar a produção de Freyre, pontua: "Sua linha de argumentação apoia-se no fato de que a cultura lusobrasileira é não apenas mestiça, como recusa a pureza étnica, característica dos regimes fascistas e nazistas da Itália e da Alemanha" (GUIMARÃES, 2002, p. 146). Partindo deste arcabouço cultural, Freyre concluiu sobre os Estados autoritários instituídos em Brasil e Portugal que, "Do ponto de vista 'social', portanto, estes regimes seriam democráticos, posto que promovem a integração e a mobilidade social de pessoas de diferentes raças e culturas" (GUIMARÃES, 2002, p. 146, 147). Se coube a Freyre nos anos 1930 conceder ao discurso de "paraíso racial" brasileiro a terminologia "democracia", foi na década de 1940 que intelectuais impactados pela leitura freyriana - particularmente Arthur Ramos e Roger Bastide - sintetizaram 
Os primórdios da black music brasileira e da linguagem política do orgulho negro nos anos 1960

sua contribuição através da expressão "democracia racial": um termo rapidamente difundido nos debates acadêmicos, na retórica parlamentar e entre movimentos negros. Deste modo, na década de 1950 o termo encontrava-se sedimentado no léxico político brasileiro como uma forma de adjetivar e caracterizar, a partir da harmonia racial, a trajetória particular do modelo democrático brasileiro (GUIMARÃES, 2002, p. 149-157).

A produção cultural brasileira também reforçou o ideal de um "paraíso racial". Heloisa Starling e Lilia Schwarcz, abordando a dimensão discursiva da canção no contexto linguístico brasileiro, mapearam em sambas e marchinhas lançados nas décadas de 1930 e 1940 a recorrência ao tema da harmonia racial. As autoras identificaram a "democracia racial" como um texto corrente na linguagem musical, dotado de um status ambíguo: algumas vezes conciliado ao estranhamento diante de episódios privados de preconceito, mas, em geral, reafirmando o ideal harmônico das relações raciais brasileiras. "Nesse sentido, o cancioneiro representa um elemento fundamental na divulgação da ideia de democracia racial que tomava vulto nesse contexto em outros lugares institucionais" (STARLING; SCHWARCZ, 2005-2006. p. 230). O próprio samba, então tornado um símbolo nacional, representava esse ideal. Na canção "Pra que discutir com madame?" (J. Almeida/H. Barbosa), lançada por Janet de Almeida em 1945, uma "madame" preconceituosa com o gênero musical identifica na "mistura de raças" que o "samba, brasileiro, é democrata" (STARLING; SCHWARCZ. 2005-2006, p. 217). Portanto, a canção tomou parte no processo de sedimentação e difusão da "democracia racial" como forma de expressar o ideal de harmonia racial no Brasil, contribuindo para a fixação do termo não apenas no léxico político, mas na própria linguagem popular cotidiana.

No início da década de 1950, quando foi criada a primeira legislação brasileira a instituir o "preconceito de cor" como contravenção penal, é possível localizar a compreensão de harmonia racial associada ao termo "democracia". O agora deputado federal Gilberto Freyre manifestou apoio à proposta de lei do companheiro de partido Afonso Arinos dizendo: "Numa tal campanha deve-se pôr em relevo o que há de antibrasileiro, antidemocrático e anticristão, tanto no racismo da direita quanto no racismo da esquerda que se tenta desenvolver entre nós." ${ }^{3} \mathrm{E}$,

\footnotetext{
${ }^{3}$ FREYRE, G. Tribuna da Imprensa, 19 jul. 1950, p.3. Apud. GRIN; MAIO. 2013, p. 35.
} 
ao despontar os anos 1960, Freyre adota a expressão "democracia racial" de forma corrente em meio à sua construção teórica do "luso-tropicalismo", afim de defender a ditadura salazarista em Portugal e seu colonialismo em território africano, e também para criticar o que o intelectual considerava como influência estrangeira sobre os negros brasileiros (GUIMARÃES, 2002, p. 160).

No ano de 1960, o conteúdo do ideal de harmonia sintetizado pela expressão "democracia racial", aparece no discurso oficial do presidente da República Juscelino Kubitschek indicando a inexistência de discriminação e preconceito racial no país: "nossa civilização não traz a mácula do preconceito racial que enodoa a cultura de outros povos. A luta comum contra o invasor, na formidável

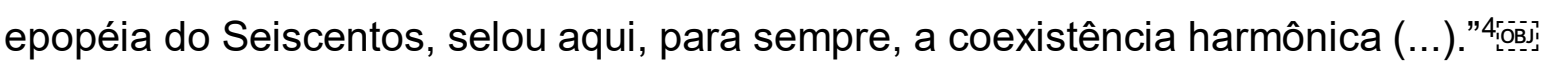
Confirmando a sedimentação do ideário, segundo Guimarães,

Os acontecimentos políticos posteriores, principalmente a vitória das forças conservadoras em 1964, farão prevalecer a ideia de Freyre de que a 'democracia racial' já estava plenamente realizada no plano da cultura e da mestiçagem, enfim, da formação nacional. (GUIMARÃES, 2002, p. 162).

Em um documento de 1968 da Escola Superior de Guerra é possível confirmar a mobilização do ideário pela ditadura militar brasileira, associado à inexistência de preconceito: "Com um orgulho racial muito reduzido o brasileiro gloria-se antes de não possuir um vero preconceito de raças." 5

Ao longo da primeira metade do século XX, portanto, o já secular discurso brasileiro de convivência racial harmônica, que escamoteia conflitos, foi sintetizado a partir do termo-chave "democracia racial". A consolidação do vocábulo possibilitou que este migrasse de um texto de status ambíguo no debate racial, para tornar-se o substrato no qual a questão racial poderia ser discutida no Brasil, sustentando um discurso oficial da inexistência de preconceito racial no país. Embora ocorressem manifestações acusando a discriminação racial, como as convenções, conferências e o congresso, organizados nos anos 1940 e 1950 pelo Teatro Experimental do Negro, mesmo a denúncia operava com o termo, denominado pelo intelectual

\footnotetext{
417 de setembro de 1960. "Agradecendo o título de cidadão do recife, conferido pela câmara de vereadores da cidade". Discursos proferidos no quinto ano do mandato presidencial, 1960, p. 336. Disponível em: <https://biblioteca2.presidencia.gov.br/repositorioinstitucional/> Acesso 30/09/2020. 5 MORAES FILHO, B. "Elementos básicos da nacionalidade as instituições" In: Segurança e Desenvolvimento, ano XVII, n. 130, Rio de Janeiro: Associação dos Diplomados da Escola Superior de Guerra, 1968, p.53. Apud KOSSLING, 2007, p. 84.
} 
Os primórdios da black music brasileira e da linguagem política do orgulho negro nos anos 1960

Florestan Fernandes "mito da democracia racial" (NASCIMENTO, 1982). Deste modo, quando miramos o cenário da década de 1960 e os termos a expressar a denúncia ao preconceito e à discriminação racial no Brasil à época, o vocábulo "democracia racial" aparece como mais do que um dos termos através dos quais a questão era discutida no léxico político, configurando o ambiente discursivo hegemônico. Assumindo a inspiração deste artigo na abordagem do Contextualismo Linguístico da História das Ideias (SKINNER, 2005; POCOCK, 2013), a expressão das linguagens políticas antirracistas no Brasil, como a difundida no cancioneiro da Black Music, defrontava um "contexto linguístico" no qual o ideal de democracia racial fornecia o ponto de partida da pauta racial e conformava o debate público.

\section{A bossa negra e a linguagem do orgulho negro}

A canção "Pra que discutir com madame?", de 1945, é exemplar do "lugar" conquistado pelo samba na afirmação da harmonia racial. Aponta um pensamento preconceituoso: "o samba tem cachaça/ mistura de raça, mistura de cor/ (...) o samba é democrata/ é música barata sem nenhum valor"; ao qual responde: "Madame tem um parafuso a menos/ só fala veneno, meu Deus que horror/ o samba brasileiro democrata/ Brasileiro na batata é que tem valor". ${ }^{6} \mathrm{~A}$ apologética conclusão do samba vai ao encontro do processo que transformou o gênero em símbolo nacional (VIANNA, 2012), incluindo a população negra por alguns elementos culturais - a música, a culinária e a capoeira -, enquanto mantinha a exclusão econômica e de políticas sociais ao grupo (SIQUEIRA, 2012) e condenava outros elementos culturais, como as práticas religiosas de matriz africana.

A consagração desse samba foi ressaltada na regravação de João Gilberto em 1985. ${ }^{7}$ João, embora baiano, foi o mais representativo nome da Bossa Nova, um movimento cultural encabeçado pela classe média branca carioca nos anos 1950 e responsável pela elaboração de uma roupagem sofisticada para o samba, tornando-o propício à valorização e consumo das classes média e alta brasileiras. A "roupagem sofisticada" se deu através de diluição da instrumentação percussiva

\footnotetext{
${ }^{6}$ Janet de Almeida e Regional Benedito Lacerda. Pra que discutir com madame/ Por essa vez passa. Compacto. Continental. 78rpm. 1945

7 João Gilberto. Live at the 19th Montreaux Jazz Festival. Álbum. WEA. 1985.
} 
e da valorização dos silêncios na estrutura musical. ${ }^{8} \mathrm{O}$ marco da proposta foi o disco compacto lançado por João em 1958 na gravadora Odeon, com as canções "Chega de saudade" e "Bim bom". Desfazendo da estrutura percussiva característica da execução dos sambas pelas comunidades negras, a Bossa Nova, apesar de angariar enorme respeito na crítica especializada e impactado uma grande geração de músicos, sofreu e ainda sofre críticas como uma forma de "embranquecimento" do samba. ${ }^{9}$

Parte das modificações da Bossa Nova, lidas como "embranquecimento" ou "sofisticação" do samba, deve-se à influência de elementos do jazz. Embora o jazz seja um gênero musical de origem estadunidense negra, a vertente que influenciou a Bossa Nova, o cool, é distinta. Formato predominantemente executado por músicos brancos, acrescentando influências da música erudita, o cool (também chamado "jazz da costa oeste") foi considerado "jazz de brancos", com impacto no mercado fonográfico na década de $1950 .{ }^{10}$ A influência do cool na Bossa Nova é ressaltada pelo historiador estadunidense Christopher Dunn ao assinalar, entre os formuladores da Bossa Nova, o gosto por "artistas de jazz da costa oeste dos Estados Unidos, como Chet Baker, Stan Getz e Gerry Mulligan, além de Miles Davis" (DUNN, 2009, p. 47). Também nos elementos textuais a Bossa Nova apresentou uma mudança, ao destacar a temática romântica e do flerte sereno à beira do mar, simbolizada pelo título do segundo álbum de João Gilberto, O amor, o sorriso e a flor (Odeon. 1960).

O impacto bossanovista foi consolidado em 1959, com o primeiro álbum de João, Chega de saudade; porém, neste ano, outro compacto lançado pela Odeon foi inovador para a música brasileira, com Elza Soares interpretando "Se acaso você chegasse" e uma versão em português para "Mack the Knife". ${ }^{11}$ "Se acaso você chegasse", originalmente gravada por Ciro Monteiro em 1938, na versão de Elza teve a segunda parte da letra substituída por uma vocalização onomatopaica, o que

\footnotetext{
${ }^{8}$ Para uma análise musicológica da contribuição de João Gilberto e, particularmente, de sua interpretação de "Pra que discutir com madame", ver: MENEZES, 2012.

${ }^{9} \mathrm{O}$ intelectual José Ramos Tinhorão destacou-se na denúncia de elitismo da Bossa Nova desde 1961, quando iniciou a coluna "Primeiras lições de samba", no Jornal do Brasil. Ver: LAMARÃO, 2008. Ou, mais recentemente, WILLIAM, 2019, p. 145-158.

${ }^{10}$ Sobre o cool jazz, ver CALADO, Carlos. Coleção Folha Jazz. Ed. Mediafashion, 2007, vol. 07 (Chet Baker) e CALADO, Carlos. Coleção Folha Lendas do Jazz. Ed. Mediafashion, 2017, vol. 19 (Stan Getz)

${ }^{11}$ Elza Soares. Se acaso fosse chegasse/Mack the knife. Compacto 78rpm. Odeon. 1959.
} 
Os primórdios da black music brasileira e da linguagem política do orgulho negro nos anos 1960

no jazz é chamado de scat. A criação da técnica do scat é atribuída a Louis Armstrong em uma gravação de 1926, "Hebbie Jeebies", e teve grande difusão a partir da performance deste artista. Embora Elza alegue que no início de sua carreira desconhecia Armstrong e atribua a sua vocalização à emulação de ruídos ao carregar uma lata d'água (CAMARGO, 2019, p. 165), é sugestivo que em seu primeiro registro na Odeon inclua uma versão de "Mack the Knife", canção gravada por Armstrong em 1956, ${ }^{12}$ frequente nos shows do cantor. Se Elza não conhecia Armstrong, os executivos da Odeon decerto o reconheciam e a gravação indicia uma aproximação. A roupagem instrumental das canções trazia elementos jazzísticos distantes da contenção da Bossa Nova ao acentuar a marcação percussiva (em "Se acaso você chegasse") e a utilização de instrumentos de sopro (saxofones, trompetes e trombones) e do scat em todo o andamento de ambas.

Com o sucesso do compacto de Elza foi lançado em 1960 seu álbum de estreia, mesmo ano do lançamento de O amor, o sorriso e a flor de João Gilberto. $\mathrm{Na}$ capa do disco, abaixo do título Elza Soares aparece o enunciado: "a bossanegra", reforçando a cor de pele explicitada pela fotografia da cantora, o que sugere um contraponto à Bossa de João, um cantor branco nos padrões brasileiros de classificação racial. ${ }^{13} \mathrm{Na}$ contracapa, o enunciado é explorado em um texto que aborda a biografia da cantora, díspar da que marca as classes médias cariocas.

\footnotetext{
Tenho 21 anos, fui mãe de seis filhos, encarei muita fábrica de sabão e cantava no clubinho do bairro por 'duzentas pratas' a sessão (...) sua alegria de cantar é autêntica porque encerra uma lição de vida. ELZA É MORRO QUE DESCEU PARA O ASFALTO... BATEU NA PORTA DO RITMO, E ALI RESOLVEU MORAR...14
}

O termo "a bossa-negra", presente no primeiro disco como um enunciado, tornouse o título do segundo álbum de Elza, lançado no mesmo ano, 1960, e explicado por ela no encarte de uma reedição de A Bossa Negra, em 2003:

\footnotetext{
12 Louis Armstrong and his All Stars. Mack the knife/Back o'town blues. Single. 45rpm. Columbia/Phillips. 1956.

${ }^{13}$ Sobre as classificações raciais brasileiras, SCHWARCZ, 2012.

${ }^{14}$ Trecho do texto original do LP de Elza Soares. Elza Soares. Álbum. Odeon. 1960. Caixa alta no original.
} 
Mas o disco nasceu por causa do Ronaldo Bôscoli. Na época ele escrevia para a revista 'O Cruzeiro'. Ele achou que eu seria uma figura importante, representativa da raça negra, e disse assim: 'é isso o que eu estou procurando! Você vai ser a representante que a gente tanto buscou! $\mathrm{E}$ vamos fazer um disco que vai se chamar 'A Bossa Negra'. ${ }^{15}$

A definição de "bossa negra" a Elza, porém, não apenas situa uma pessoa entrecruzada pelos marcadores sociais de diferença cor, gênero e classe social. Ela enuncia a sonoridade de seus álbuns, uma significativa diferença em relação à "contenção" que caracterizava a proposta da Bossa Nova. Os discos lançados por Elza não apresentam o repertório tradicional da Bossa Nova - composições de Tom Jobim, Vinícius de Moraes e Carlos Lyra, por exemplo - e tampouco os arranjos intimistas associados ao gênero. São discos "encorpados", explorando naipes de sopros e acentuada marcação percussiva, envolvendo o vocal potente da cantora como definido no texto do primeiro álbum, "voz de trombone rouco" -, abrindo espaço a seus característicos scats. A identidade estética de Elza buscou no timbre do trombone o principal parceiro aos improvisos vocais, resultando em recorrentes duelos entre scats e solos do instrumento. Distante da estética "um banquinho e um violão", representativa da Bossa, os discos de Elza aproximam-se da sonoridade das gafieiras, orientação estética que permaneceu no decorrer de seus lançamentos seguintes na década de 1960.

A referência à "bossa negra" também poderia situar outro artista surgido no mercado fonográfico brasileiro no início dos anos 1960. Jorge Ben lançou o primeiro compacto em 1963, com suas composições "Mas que nada" e "Por causa de você, menina". ${ }^{16}$ As canções valorizavam a original batida de violão de Jorge e a forte presença de instrumentos de sopro. O álbum de estreia do cantor foi lançado ainda em 1963 em tom de manifesto: Samba Esquema Novo. Na contracapa, um texto do produtor Armando Pittigliani, apresentava o artista e seu estilo:

É o esquema novo do samba. Talvez um retorno mais acentuado à nossa música popular primitiva, agora com as características modernas - mas, sem ser "bossa nova", aquela "bossa nova" dos primeiros tempos (...)

\footnotetext{
15 Trecho do encarte à reedição do LP de Elza Soares. A Bossa Negra. Álbum. Odeon. 1960. Dubas/EMI. 2003.

${ }^{16}$ Jorge Ben. Mas que nada/Por causa de você, menina. Compacto. Philips. 1963.
} 
Os primórdios da black music brasileira e da linguagem política do orgulho negro nos anos 1960

Reparem que a influência "negróide" transborda em todos os momentos de sua música. (...) Seu inato talento musical proporcionou-lhe descobrir uma nova "puxada" para o nosso samba - fazendo do violão um instrumento, sobretudo, de ritmo. (...) Há em suas letras e melodias toda a nostalgia do sangue negro, todo o encanto da poesia pura e simples do brasileiro autêntico, todo o ritmo empolgante de quatro séculos de civilização baseada numa miscigenação de raças onde o negro africano tem papel preponderante. Da Etiópia vieram seus ancestrais. De nobre linhagem indígena Jorge tirou de sua vó o sobrenome Ben. ${ }^{17}$

O texto, assim, reafirmava o ideal brasileiro de miscigenação, mas trazendo o negro para um lugar de destaque. Apesar de demarcar que não seria bossa nova, não são incomuns referências posteriores que situam os primeiros discos de Jorge na etiqueta estética bossanovista. Em 1968 o álbum foi incluído por Julio Medaglia no ensaio "Balanço da Bossa Nova" (PAIVA, 2015, p. 29); e no relançamento dos discos do artista em 2009, a jornalista Ana Maria Bahiana apresenta: "O primeiro álbum de Jorge Ben Jor aterrissou na música brasileira quase como um objeto não identificado. O padrão estético era o da bossa nova: cool, complexo e civilizado." 18 O "Esquema Novo" do samba, portanto, pôde ser associado à Bossa Nova, e, com a identificação à "influência negróide", estimula a tomada de empréstimo do epíteto Bossa Negra, atribuído à performance de Elza Soares, orientação estética presente nos quatro primeiros discos de Jorge, lançados entre 1963 e 1965 pela gravadora Philips. Seu quinto álbum, O Bidú - silêncio no Brooklin, lançado em 1967 pela gravadora Copacabana, hibridava o samba à sonoridade elétrica do rock; e o seguinte, Jorge Ben, lançado em 1969 pela Philips, desenvolvia a proposta rítmica ao violão, porém, afastando da orientação sambajazz inicial.

Uma terceira proposta identificada como "música moderna negra" foi lançada em dezembro de 1961 em um compacto com o chácháchá "Terezinha" e o rock "Biquinis e borboletas" por Wilson Simonal, artista que teve toda sua carreira fonográfica até 1971 na gravadora Odeon. No primeiro álbum, Tem Algo Mais (1963), o texto de apresentação, escrito por Ricardo Galeno, situa o disco na Bossa Nova: "surgiu com alguma influência jazzística, é verdade, mas dizendo

\footnotetext{
17 Trecho do texto original do LP de Jorge Ben. Samba Esquema Novo. Álbum. Philips. 1963.

${ }^{18}$ Trecho da contracapa à reedição em CD de Jorge Ben. Samba Esquema Novo. Universal Music. 2009.
} 
REALMENTE o nosso ritmo e o nosso sentimento. É, portanto, coisa nossa. (...) Esta produção, senhores, representa um tratado definitivo da BOSSA NOVA. ${ }^{19: 000 \text { b] }] \text { ] }}$ No álbum seguinte, A nova dimensão do samba (1964), o texto de Sérgio Lobo assinalava duas músicas, "Nanã" e "Mais valia não chorar", com o "que alguns críticos denominaram de afro-samba. ${ }^{20}$ :obobj] Tal qual o álbum de estreia de Jorge Ben, o segundo álbum de Simonal era intitulado em tom de manifesto e trazia hibridações entre o samba e o jazz, com arranjos explorando instrumentos de sopro. O artista prosseguiu nesta sonoridade nos dois álbuns seguintes, Wilson Simonal e S'imbora, lançados em março e novembro de 1965. A partir de 1966, porém, Simonal criou uma proposta musical que the permitiu angariar enorme sucesso popular e comercial. Sintetizando a referência musical sambajazz em um trio, o Som3, mas tocando também canções com temáticas juvenis, como as que faziam sucesso na cena rockeira nacional da Jovem Guarda, nascia a Pilantragem.

Elza, Jorge e Simonal iniciaram a carreira no mercado fonográfico no início da década de 1960 e tiveram suas performances lidas como propostas estéticas de teor inovador e demarcadas por sua condição de pessoas negras. E, nas três propostas, parte de sua inovação era identificada em diálogos com o jazz. Esses diálogos eram feitos a partir de um processo de hibridação do samba, gênero símbolo da identidade cultural brasileira, com o estilo de Louis Armstrong (no caso de Elza) e com o hard bop e o souljazz/funky, subgêneros do jazz estadunidense representativos das comunidades negras dos EUA.

Em uma sociedade marcada pela segregação racial em grande parte do território desde o século XIX, o mercado fonográfico dos EUA refletiu a separação. As empresas de disco que começaram a investir em produtos musicais para as comunidades negras por volta de 1920, estabeleceram para este mercado o selo race-records (HOBSBAWM, 2009. p, 82), que na década de 1940 foi rebatizado rythmand blues (MAZZOLENI, 2012. p, 57) e que até a década de 1960 deu origem ao termo Black music. O trompetista e cantor Louis Armstrong é o representante mais consagrado do New Orleans, um dos primeiros subgêneros do jazz nos EUA, registrado em disco no início na década de 1920 como diferenciação a um tipo

\footnotetext{
${ }^{19}$ Trecho do texto original do LP de Wilson Simonal. Tem algo mais. Álbum. Odeon. 1963. Caixa alta no original.

${ }^{20}$ Sergio Lobo. Texto original do LP de Wilson Simonal. A nova dimensão do samba. Álbum. Odeon. 1964.
} 
Os primórdios da black music brasileira e da linguagem política do orgulho negro nos anos 1960

similar de execução realizada por jazzistas brancos, o Dixieland (CALADO, 2007, vol. 2), configurando os primórdios da definição segregacionista race-records. Já o hard Bop e o souljazz (ou Funky) chegaram aos fonogramas nos anos 1950 como uma resposta de músicos negros ao sucesso comercial do cool, o "jazz de brancos". Em um contexto de impacto do movimento pelos Direitos Civis nos EUA, o hard bop e o souljazz angariaram dimensão política ao reafirmar a herança do Blues e da musicalidade das igrejas protestantes negras, o Gospel, enquanto matrizes da música negra no país. Entre os destaques desses gêneros estão Horace Silver, Art Blakey \& os Jazz Messengers e Lee Morgan. (CALADO, 2007, vol. 5; vol. 10; e vol. 20).

Embora o impacto do cool tenha angariado maior visibilidade no Brasil dos anos 1950 através da Bossa Nova, o hard bop também foi difundido em terras brasileiras entre os anos 1950 e 1960. Inspirados por Johnny Alf, um músico negro brasileiro tido como um dos precursores da Bossa Nova e fã do jazzista negro Nat King Cole, ${ }^{21}$ os músicos influenciados pelo hard bop tiveram suas performances definidas pelo termo "Sambajazz" - ou "Hard Bossa Nova" (GOMES, 2010). Atuavam principalmente em grupos instrumentais, como o Copa Trio, liderado pelo pianista negro Salvador, que tocou com Elza Soares, Jorge Ben e Simonal. Salvador gravou quatro álbuns instrumentais emblemáticos da sonoridade sambajazz entre os anos de 1965 e 1966, mais próximos do hard bop do que do samba; dois deles creditados como Rio 65 Trio, pela gravadora Philips (Rio 65 Trio, de 1965; e A hora e a vez da M.P.M, de 1966), e outros dois creditados como Salvador Trio, pela gravadora Mocambo (Salvador Trio, de 1965; e Tristeza, de 1966).

$\mathrm{Na}$ audição dos discos de Elza, Jorge, Simonal e Salvador é possível, portanto, identificar uma proposta musical realizada por artistas negros que incorporaram e reelaboraram influências da música negra estadunidense, realizando um produto híbrido, uma Bossa Negra: o primórdio da Black Music Brasileira. Contudo, além da roupagem musical, as letras de uma série dessas canções ressaltam a temática racial em uma leitura antirracista.

A temática antirracista faz parte do cancioneiro popular brasileiro desde os primórdios das gravações musicais no início do século XX. Partindo da experiência

${ }^{21}$ Sobre Johnny Alf e sua reverência a Nat King Cole, ver CASTRO, Ruy. Johnny Alf. Coleção Folha: 50 anos de Bossa Nova. Vol. 08. Rio de Janeiro: MEDIAfashion, 2008. 
cotidiana dos compositores, os fonogramas documentaram, em meio a ampla variedade temática, eventuais mensagens que pautavam a marginalização das comunidades negras e a existência do preconceito. Exemplos da temática no texto de compositores negros são sambas como "A favela vai abaixo", de Sinhô, interpretada por Francisco Alves (1928), sobre a intervenção do Estado nas habitações irregulares; 22 "Professor de violão", de Sinhô na voz de Januário de Oliveira (1929), e "Preconceito", de Wilson Batista e Marino Pinto interpretada por Orlando Silva (1941), ambas denunciando o "preconceito de cor" no Brasil. Também a referência à religiosidade de matriz africana apareceu na música comercial nos anos 1940, a partir das reverências à orixá lemanjá pelo compositor e cantor baiano Dorival Caymmi (DUNN, 2009, p. 203).

No repertório da Bossa Negra é perceptível que a temática antirracista conquista maior frequência e amplitude. Nos quatro primeiros álbuns de Elza Soares, lançados entre 1960 e 1963, a abordagem às vezes aproxima do discurso hegemônico ao reafirmar o estereótipo sensual da "mulata" (a personificação da "democracia racial") nas canções "Mulata Assanhada" (1960), "As polegadas da mulata" (1960) e "Mulata de verdade" (1963). Já "Nego tu... nego vós... nego você" (1960) diversifica a inserção social do negro (um com "panca de doutor", outro que "trabalha no comércio" e consegue ascensão social, e o que "não trabalha e vive bem"); enquanto "Cantiga do morro" (1961) denuncia o preconceito à população das favelas e a desumanização no estigma da criminalidade ("Vê bandido em qualquer morador/ Não vê pai, não vê mãe, nem avô/ Ninguém nos vê como gente e assim/ só vê o que há de ruim"). O preconceito também aparece em "A banca do distinto" (1963) que questiona: "Não fala com pobre/ Não dá mão a preto/ Não carrega embrulho/ Pra que tanta pose, doutor?"; e em "Maria, Maria, Maria" (1963), que retoma a figura da mulata, mas narrando um caso de ascensão social, apresentada pelo termo "embranquecimento":

Maria que desceu do morro pra cozinha/ (...) Um dia descobriu-se, descobriram a moça/ Um dono de boate logo a fez brilhar/ Maria já não faz o que é mandada/ Agora é jamete, já não é mulata/ Trocou a luz de vela pelo refletor/ Maria não tem mais problema financeiro/ Trabalha muito menos, ganha mais dinheiro/ Enquanto ela deu duro, não deram valor/ (...)

${ }^{22}$ Para uma análise desta canção, ver VIEIRA, 2011. 
Os primórdios da black music brasileira e da linguagem política do orgulho negro nos anos 1960

Maria não tem mais complexo nem nada/ Está realizada e eu sem empregada/ É mais uma escurinha que embranqueceu.

O ano de 1963 trouxe maior amplitude para a Bossa Negra com a estreia em álbum de Jorge Ben e Wilson Simonal. Se o primeiro álbum de Simonal, Tem algo mais, não trouxe referências à temática antirracista, o autoral Samba esquema novo, de Jorge, representou um alargamento da referência à cultura afro-brasileira desde o primeiro sucesso, "Mas que nada" (que inicia e encerra exaltando a orixá Obá e apresenta-se como "samba de Preto Velho"), também em "A tamba" ("A conga está chamando/ vamos todos até lá/ Pois a tamba está tocando/ (...) Desde que se foi/ o nosso Rei Nagô/ Ninguém jamais fez samba") e "Ualá, ualalá", que encerra com um pedido de licença ou proteção ("Agô") à orixá Obá, esposa de Xangô. No ano seguinte, 1964, Jorge lançou dois álbuns (Sacudin Ben samba e Ben é samba bom) nos quais referências à cultura afro-brasileira aparecem em "Capoeira", "Gimbo" (com as palavras de origem africana "gimbo" ["moeda"] e "emoriô" [uma saudação]); "Jeitão de Preto Velho", "Não desanima, João" ("Preto Velho, sim/ Está cansado, precisa descansar") e a musa que intitula "Dandara, hei" (uma liderança do Quilombo de Palmares, esposa de Zumbi). Em 1964 Simonal lançou A nova dimensão do samba que exaltava a orixá "Nanã" ("Essa noite quando eu vi Nanã/ Vi a minha deusa ao luar") e na canção "Samba de negro" referencia o orixá Xangô. Todas essas canções foram lançadas antes do celebrado álbum Os afro sambas (1966), de Baden Powell e Vinícius de Moraes, que articulava a reverência aos Orixás com uma roupagem musical inspirada no Candomblé.

Em 1965, o álbum de Elza Soares (Um show de Elza) escapa da temática e da estética da Bossa Negra, aproximando-se do samba-canção; mas o de Jorge Ben (Big Ben), seu último na sonoridade sambajazz, faz reverência a uma entidade religiosa da Umbanda e a uma bebida dos povos bantos em "Maria Conga" ("Já chegou Maria Conga vendendo o seu Aluá") e à orixá lansã em "Agora ninguém chora mais". E nos dois álbuns lançados por Simonal, Wilson Simonal e S'imbora, há as canções "Ladeira do pelourinho", na qual um pedido de intervenção ao orixá Oxalá, por intermédio do Babalorixá, busca resolver o efeito de uma oferenda ("Dá me um pouco de paz, Oxalá (...)/ Que estou amarrado a um olhar, um olhar Candomblé/ Isto foi Ebó, na ladeira está/ Vou descer agora e dizer a meu 
Babalorixá.") e o medley "Opinião/O morro não tem vez/Batucada surgiu", aborda a resistência à política de remoções forçadas em favelas cariocas. ${ }^{23}$

Os próximos lançamentos demonstraram mudanças estéticas: Jorge uniuse a uma banda elétrica de rock (Bidú: Silêncio do Brooklin, 1967), Simonal fundou a Pilantragem (Vou deixar cair, 1966; e a série anual de 4 volumes Alegria, alegria, entre 1966 e 1969) e Elza adotou o hard bop do sambajazz (Com a bola branca, 1966, e O máximo em samba, 1967), gravou sambas mais tradicionais em parcerias (Elza, Miltinho e samba, 1967, Elza, Miltinho e samba 2, 1968; e Elza. Baterista: Wilson das Neves, 1967) e retomou sua roupagem estética original, fortalecida por destacada instrumentação de percussão (Elza, carnaval \& samba, 1969). Na fase sambajazz, Elza apresentou a canção "Quizumba" (1966), que proclama "Eu preciso ir na macumba pra tirar essa quizumba que jogaram em cima de mim".

A abordagem da questão racial pelos artistas da Bossa Negra ampliou a linguagem antirracista na canção brasileira com a evocação de temas da cultura e experiências das comunidades negras, expressos em uma roupagem musical que incorpora e reelabora referências da música negra estadunidense. Esse diálogo com as experiências raciais estadunidenses para elaborar e exprimir a realidade das comunidades negras brasileiras compõe os primeiros elementos do que este artigo denomina Linguagem Política do Orgulho Negro: uma forma de entender e comunicar a experiência racial, a desigualdade e o preconceito enquanto consequências globais do racismo em sua dimensão diaspórica, a partir da herança de séculos de escravismo e da criação de diversos mecanismos de exclusão das comunidades negras no continente americano. Da herança comum, advém a formulação de manifestações estéticas e/ou estritamente políticas em resposta às formas de exclusão racial e particularidades locais, mas passíveis de diálogo com outras realidades geográficas. Tal forma de expressão, que, no primeiro movimento, no início dos anos 1960, hibridou a música produzida por comunidades negras do Brasil com a dos EUA, em um segundo movimento registrou na canção brasileira tanto a incorporação mais explícita da Black Music estadunidense, quanto uma conexão transnacional na temática racial nas letras. Seguir os movimentos dessa conexão indicia a repercussão na canção brasileira de um circuito comunicativo transnacional de experiências e da cultura política negra denominado por Paul 
Os primórdios da black music brasileira e da linguagem política do orgulho negro nos anos 1960

Gilroy O Atlântico Negro (2012) em um estudo centrado no contexto anglófono, mas que enfatiza a relevância da produção musical neste fluxo da diáspora negra.

\section{Da bossa negra ao black soul}

No segundo semestre de 1967, a circulação de referenciais estadunidenses na canção brasileira foi intensificada com o lançamento, por Wilson Simonal, de "Tributo a Martin Luther King". A canção era uma das raras composições de Simonal, feita em parceria com Ronaldo Bôscoli e não era uma Bossa Negra ou Pilantragem, mas um spiritual, uma das matrizes da música negra estadunidense, ancestral do gênero comercial gospel. A escolha do gênero spiritual, um veículo para a circulação da reivindicação da igualdade política nas igrejas negras dos EUA, combinava perfeitamente com o homenageado na canção, um pastor negro da vertente cristã protestante Batista e o mais destacado líder do movimento pelos Direitos Civis às comunidades negras do país. A letra da canção dizia:

Sim, sou um negro de cor,/ meu irmão de minha cor,/ o que te peço é luta,
sim, lutar mais./ Que a luta está no fim./ Cada negro que for,/ outro negro
virá para lutar./ Com sangue ou não, com uma canção também se luta,
irmão./ Ouve minha voz./ Luta por nós./ Luta negra demais é lutar pela
paz./ Para sermos iguais. ${ }^{24}$

A difusão inicial da canção ocorreu em março de 1967, antes do lançamento do compacto, quando Simonal foi convidado para abrir o show de entrega do troféu Roquete Pinto, destinado aos "melhores artistas do ano", espetáculo exibido em horário nobre pela TV Record. Simonal comemorava o bom resultado mercadológico do álbum Vou deixar cair..., inaugural da Pilantragem, e esperavase que executasse algum recente sucesso. No entanto, anunciou para a platéia uma nova canção:

Eu compus uma música de parceria com meu amigo Ronaldo Bôscoli e intitulei "Tributo a Martin Luther King". Martin Luther King é um negro norteamericano. O mérito maior de Martin Luther King é lutar cada vez mais pela igualdade dos direitos das raças. Essa música, eu peço permissão a vocês, porque eu dediquei ao meu filho, esperando que no futuro ele não encontre

\footnotetext{
${ }^{24}$ Wilson Simonal. Tributo a Martin Luther King/Deixa quem quiser falar/Ela é demais/Está chegando a hora. Compacto duplo. Odeon. 1967. Faixa 01, lado A.
} 
nunca aqueles problemas que eu encontrei, e tenho às vezes encontrado, apesar de me chamar Wilson Simonal de Castro. ${ }^{25}$

A gravação e o sucesso comercial de "Tributo a Martin Luther King" indiciou novas possibilidades aos processos de hibridação na música brasileira. A adesão explícita a um gênero da música negra estadunidense foi incorporada e reelaborada a partir da ambientação temática, permitindo a identificação de experiências semelhantes e Luther King, o destinatário da mensagem, é reconhecido como representante de uma luta comum. O sujeito da canção parte da primeira pessoa do singular, eu (o cantor brasileiro), dirigindo à segunda do singular, você (o pastor e líder político estadunidense), para sintetizar na primeira do plural, nós (as pessoas negras, em geral): "Sim, sou um negro de cor, meu irmão de minha cor/ o que te peço é luta, sim, lutar mais/ (...) Luta por nós. (...) Para sermos iguais."

Nos anos seguintes, as performances realizadas por Simonal registraram, através do documento fonograma, outras incorporações explícitas da Black music estadunidense, como no álbum Alegria, Alegria vol.3 (1969), no qual haviam as gospel "Silêncio" e "Aleluia Aleluia"; as canções soul "Mustang cor de sangue" e "Prece ao vento" e o funk "What you Say", cantada em inglês, a "língua da matriz", como anunciado na abertura da canção. $O$ álbum, portanto, consolidava a trajetória de interlocução estética registrada por Simonal, e fixava na indústria fonográfica uma forma de expressão que na década seguinte seria denominada de Black Soul.

Entre "Tributo..." e Alegria, Alegria, vol. 3 de Simonal, a indústria fonográfica brasileira apresentou o primeiro registro fonográfico de Tim Maia, lançado em 1968 pela gravadora CBS: um compacto que incluía as canções de sua autoria "Meu país" e "Sentimento", ambas na estética soul. O disco não conquistou repercussão comercial ou de crítica e as canções seriam conhecidas de grande público quando o próprio artista as regravou em álbuns lançados na década de 1970. "Meu país", contudo, também apresentava uma letra que aproximava, de forma comparativa, as realidades raciais brasileira e estadunidense:

Sim/ Bem sei que aprendi/ Muito no seu país/ Justo no seu país/ Porém no meu país/ Senti tudo que quis/ Pois vi/ Como vivem todas as flores/ Todas

25 Texto transcrito a partir da cena registrada em vídeo. Disponível em: <https://www.youtube.com/watch?v=FHOWs4Sw0ZE> Último acesso em 30/09/2020. 
Os primórdios da black music brasileira e da linguagem política do orgulho negro nos anos 1960

as dores/ Sem distinção de cor/ O amor existe, enfim/ Mesmo ainda/ Quando a luta/ Do alto se escuta/ Em uma só voz que diz/ Somos como irmãos. ${ }^{26}$

Diferente da composição de Simonal, que constatava a existência de preconceito racial no Brasil, a composição de Tim reafirmava o discurso oficial de convivência harmônica e inexistência de preconceito racial no país, discurso sintetizado pela expressão "democracia racial". É interessante considerar a diferença entre as leituras da realidade racial brasileira demonstradas por Simonal, um cantor que vivia no Brasil e apresentava uma posição política conservadora, apoiando a ditadura militar presente no país ${ }^{27}$ e Tim, que há pouco voltara de uma temporada vivendo nos Estados Unidos da América no contexto de eclosão de conflitos raciais no movimento pelos Direitos Civis.

No efervescente cenário político da discussão racial nos EUA dos anos 1960, a música pop soul, ao propiciar o casamento entre melodia e letra, repercutia de forma mais engajada do que os subgêneros jazzísticos, prioritariamente instrumentais. Apropriada como "trilha sonora" do movimento pelos Direitos Civis das pessoas negras do país, (VIANNA, 1987, p. 45.) a música soul muitas vezes veiculava mensagens politizadas em canções de grande sucesso comercial, como as lançadas por Sam Cooke ("A change is gonna come" [A mudança está por vir], 1964), The Impressions ("Keep on Pushing" [Continue empurrando], 1964 ou "People Get Ready" [Povo, prepare-se], 1965) ou James Brown (o funk "Say it loud, I'm Black and I'm proud" [Diga alto, sou negro e tenho orgulho], 1968).

Além de Simonal, outro artista da Bossa Negra incorporou a sonoridade soul e funk: o pianista Salvador. Depois de lançar quatro álbuns com o Rio 65 Trio e o Salvador Trio, entre os anos 1965 e 1966, e ter acompanhado diversos cantores (notoriamente Elis Regina), o pianista gravou um álbum em 1969, pela CBS, intitulado pelo nome que então adotara: Dom Salvador. O disco instrumental apresentava releituras de várias músicas lançadas em seus álbuns anteriores e algumas novas composições, executadas em instrumentos elétricos, com destaque ao órgão, tocado por Salvador, a guitarra e o contra-baixo. As roupagens soul e funk

\footnotetext{
${ }^{26}$ Tim Maia. Meu país/Sentimento. Compacto. CBS. 1968.

27 Para uma análise detalhada do posicionamento conservador de Simonal em relação com sua postura antirracista, ver MORAIS, 2019, p. 245-265.
} 
ainda traziam hibridações, com a inclusão de cuíca em duas das canções. No texto de apresentação do disco, o artista era apresentado: "Dom Salvador! Síntese brasileira da música negra no mundo". A sonoridade conquistada por Salvador neste disco foi essencial para o próximo trabalho lançado pelo artista, em 1971, com a fundação do grupo Abolição e o lançamento do hoje cultuado álbum Som, sangue e raça, uma das bases do que viria a ser a Banda Black Rio, além da sua produção dos arranjos dos dois álbuns de Tony Tornado, um dos primeiros astros do Black Soul Brasileiro.

\section{Conclusão}

Este artigo apresentou os primórdios da Black Music Brasileira na década de 1960, com o surgimento da Bossa Negra, termo através do qual foi tratada tanto a produção de Elza Soares, que articulava o samba ao jazz de Louis Armstrong; quanto o sambajazz de Jorge Ben, Wilson Simonal e Salvador, que desenvolveram o hard bop e o funky na Bossa Nova brasileira. Na segunda metade da década, Simonal e Salvador, artistas de sólida carreira na indústria fonográfica brasileira, incorporaram outras sonoridades da Black Music estadunidense, como o gospel, o soul e o funk, sedimentando a formulação de uma Black Music Brasileira.

No repertório selecionado foi identificada a veiculação de uma série de temas sobre a questão racial no Brasil - o preconceito, a questão habitacional e a cultura negra, particularmente a religiosidade afro-brasileira - em uma abordagem antirracista. $\mathrm{O}$ diálogo entre as realidades de comunidades negras brasileiras e estadunidenses, inicialmente documentado na incorporação e reelaboração de gêneros musicais, na segunda metade da década foi registrado em conexões com formas de atuação política antirracista. O conceito de Linguagem Política do Orgulho Negro visa abarcar essas formas de expressão da realidade racial brasileira, que estabelecem conexões com experiências estéticas e de atuação política afro-estadunidenses, em uma forma de comunicação que tensiona o discurso nacional, conformado no contexto linguístico da democracia racial. Tal linguagem estética e temática seria expressa com maior intensidade a partir da década de 1970, em uma postura racial afirmativa da negritude, contraposta à "identidade mestiça" construída como símbolo nacional brasileiro. 
Os primórdios da black music brasileira e da linguagem política do orgulho negro nos anos 1960

Artigo recebido em 09 de outubro de 2020. Aprovado para publicação em 09 de janeiro de 2021.

\section{Bibliografia}

CALADO, Carlos. Coleção Folha Jazz. Rio de Janeiro: Mediafashion, 2007, vol. 07 (Chet Baker), vol. 2 (Louis Armstrong), vol. 5 (ArtBlakey); vol. 10 (Horace Silver); e vol. 20 (Lee Morgan).

CALADO, Carlos. Coleção Folha Lendas do Jazz. Rio de Janeiro: Mediafashion, 2017, vol. 19 (Stan Getz).

CAMARGO, Zeca. Elza. Rio de Janeiro: Ed. Leya, 2019.

CANCLINI, Nestor G. Culturas Híbridas: estratégias para entrar e sair da modernidade. 4 ed. São Paulo: UNESP, 2008.

CASTRO, Ruy. Coleção Folha 50 anos de Bossa Nova. Rio de Janeiro: MEDIAfashion, 2008. Vol. 08 (Johnny Alf).

DUNN, Christopher. Brutalidade Jardim: Tropicália e o surgimento da contracultura brasileira. São Paulo: Ed. Unesp, 2009.

GILROY, Paul. O Atlântico Negro: modernidade e dupla consciência. São Paulo: Editora 34, 2012.

GOMES, Flávio. Negros e política (1888-1937). Rio de Janeiro: Jorge Zahar, 2005.

GOMES, Marcelo. Samba-jazz aquém e além da Bossa Nova: três arranjos para Céu e Mar de Johnny Alf. Tese (Doutorado). Departamento de Música. UNICAMP, Campinas, 2010

GRIN, Mônica; MAIO, Marcos C. O antirracismo da ordem no pensamento de Afonso Arinos de Melo Franco. Topoi, v. 14, n.26, jan/jul. 2013, p. 33-45.

GUIMARÃES, Antonio S. A. Classes, raça e democracia. São Paulo: Editora 34. 2002.

HOBSBAWM, Eric. História social do jazz. 6 ed. Rio de Janeiro: Paz e Terra, 2009.

IGLÉSIAS, Francisco. Segundo Momento: 1838-1931. In: Historiadores do Brasil. $2^{\circ}$ impressão. Rio de Janeiro: Nova Fronteira; Belo Horizonte: IPEA, 2000, p. 65-72.

KOSSLING, Karin. As lutas anti-racistas de afro-descendentes sob vigilância do $D E O P S / S P$. Dissertação (Mestrado). Departamento de História, USP, São Paulo, 2007. 
LAMARÃO, Luisa Q. As muitas histórias da MPB. As ideias de José Ramos Tinhorão. Dissertação (Mestrado). Departamento de História, UFF, Rio de Janeiro, 2008

MAZZOLENI, Florent. As raízes do rock. Rio de Janeiro: Cia Editora Nacional, 2012.

MENEZES, Enrique V. A música tímida de João Gilberto. Dissertação (Mestrado). Departamento de Belas Artes. USP, São Paulo, 2012.

MORAIS, Bruno V. L. Sim, sou um negro de cor: Wilson Simonal e a afirmação do Orgulho Negro no Brasil dos anos 1960. Dissertação (Mestrado). Departamento de História. UFMG, 2016.

MORAIS, Bruno V. L. Um antirracismo liberal conservador? Orgulho Negro e denúncia do racismo por Wilson Simonal nos anos 1960. In: BOHOSLAVSKY, E.; MOTTA, R.; BOISARD, S. Pensar as direitas na América Latina. São Paulo: Alameda, 2019, p. 245-265.

NASCIMENTO, Abdias do. O Negro revoltado. 2. ed. Rio de Janeiro: Nova Fronteira, 1982.

PAIVA, Carlos E. A. Black Pau: a soul music no Brasil anos 1970. Tese (Doutorado). Departamento de Ciências Sociais. UNESP, 2015.

POCOCK, John G. A. Linguagens do Ideário Político. Sergio Miceli (Org.). São Paulo: Ed. UNESP, 2013.

SCHWARCZ, Lilia. Nem preto nem branco, muito pelo contrário. Cor e raça na sociabilidade brasileira. São Paulo: Claro Enigma, 2012.

SIQUEIRA, Magno B. Samba e identidade nacional: das origens à era Vargas. São Paulo: Editora Unesp, 2012.

SKINNER, Quentin. Visões da Política. Sobre métodos históricos. Portugal: Difel, 2005.

STARLING, Heloísa; SCHWARCZ, Lilia. M. Lendo canções e arriscando um refrão. Revista USP, n68, São Paulo, Dez/Fev. 2005-2006, p.210-233.

VIANNA, Hermano. O Baile funk carioca: Festas e Estilos de Vida Metropolitanos. Dissertação (Mestrado), Depto. de Antropologia, UFRJ, Rio de Janeiro, 1987.

VIANNA, Hermano. O Mistério do samba. Rio de Janeiro: Zahar, 2012.

VIEIRA, Juliana Lessa. A Questão Habitacional em Ritmo de Samba - Uma Análise do Ponto de Vista dos Trabalhadores Cariocas Durante as Reformas Urbanas (1900-1930). Anais do XXVI Simpósio Nacional de História - ANPUH, São Paulo, julho 2011.

WILLIAM, Rodney. Apropriação Cultural. São Paulo: Pólen, 2019. 